\title{
Fatores associados ao trabalho de operadores de checkout: investigação das queixas musculoesqueléticas
}

\author{
Clarissa Stefani Teixeira UFSC \\ Maricel Karina López Torres UFSC \\ Antonio Renato Pereira Moro UFSC \\ Eugenio Andrés Díaz Merino UFSC
}

\section{RESUMO}

Este artigo buscou verificar os fatores associados à dor musculoesquelética expressa por operadores de checkout. Participaram do estudo 48 trabalhadores que responderam ao questionário nórdico para identificação da presença de queixas musculoesqueléticas e a um questionário multidimensional com aspectos sociodemográficos de saúde e de condições de trabalho. Para a análise dos dados, foi utilizada a correlação de Spearman para associações, Qui-Quadrado e teste exato de Fisher para testar a homogeneidade das queixas em relação às variáveis socioeconômicas de saúde e de condições do trabalho. Os resultados indicam condições de trabalho não conformes com a NR-17, as quais se relacionam com os sintomas musculoesqueléticos principalmente na região superior das costas. Além disso, os afastamentos por queixas relacionaram-se de forma mais forte aos joelhos e ao exercício de outro trabalho remunerado.

\section{Factors related to the work of checkout operators: research musculoskeletal complaints}

\begin{abstract}
This article aims to evaluate the factors associated with complaints of musculoskeletal pain expressed by checkout operators. Participants in the study were 48 employees who responded to the Nordic questionnaire to identify the presence of musculoskeletal complaints, and a multidimensional questionnaire covering aspects of socio-demographics, health and working conditions. For data analysis it used Spearman's correlation to test for associations, chisquare and Fisher's Exact Test to test the homogeneity of complaints related to socioeconomic variables, health and working conditions. The results indicate a lack of compliance with the NR-17 on working conditions, and relate to musculoskeletal symptoms, especially in the upper back. Moreover, job loss due to such complaints related preponderantly to knee problems and the carrying out of other paid work.
\end{abstract}




\section{INTRODUÇÃO}

A busca pela maior produtividade e qualidade das atividades desenvolvidas no trabalho, que cada vez mais tende a ser industrializado, mecanizado e automatizado, pode impor condições prejudiciais à saúde do trabalhador. As posturas adotadas durante as horas trabalhadas influenciam as queixas relatadas pelos indivíduos e os movimentos realizados para a execução das tarefas, muitas vezes, estão relacionados com problemas musculoesqueléticos.

O posto de trabalho, quando não ajustado corretamente, tem relação com muitos problemas encontrados nos trabalhadores. Neste sentido, a ergonomia vem auxiliar no desenvolvimento de postos de trabalho que contribuam para reduzir as exigências biomecânicas e cognitivas do operador, possibilitando a adoção de uma postura mais adequada (IIDA, 2005).
1994; CANDEIAS, 1997); para os indivíduos trabalhadores, há sofrimento, levando-os a um nível de incapacidade não só para o trabalho mas para grande parte das atividades cotidianas e sociais usuais (DE VITTA; BERTAGLIA; PADOVANI, 2008). Somadas a isto, as consequências para os trabalhadores alastram-se por sua vida profissional, social e econômica (GUÉRIN et al., 2001).

Tamanha é essa preocupação que, em março de 2007, o Ministério do Trabalho e Emprego aprovou o Anexo I da NR-17 (Portaria n. ${ }^{\circ} 8,30 / 05 / 2007$ ), que trata das condições de trabalho de operadores de checkout. Neste caso, o posto de trabalho pode contribuir para o aparecimento de dor/ desconforto no trabalho, interferindo na qualidade de vida e na saúde dos trabalhadores (BRASIL, 2007), além de no desempenho produtivo.

Partindo dessas considerações, este estudo objetivou verificar os fatores associados à dor musculoesquelética sofrida por operadores de checkout em um supermercado a partir de queixas formalizadas pelos trabalhadores. Com esta análise, esperase contribuir com a indicação de aspectos que possam ser melhorados ou transformados, no âmbito do trabalho, para a melhor realiza-

Diversas profissões vêm sendo estudadas, evidenciando-se a necessária identificação de riscos e condicionantes ergonômicos decorrentes dos resultados esperados no atendimento aos objetivos que uma empresa se propõe na realização das atividades de forma singular (GUERIN et al., 2001). A operação de checkout de supermercados pode ser citada entre elas devido às posturas corporais em que os operadores destes realizam sua atividade e devido às características dos postos de trabalho (SOUZA, 2007). Assim como afirmam Battisti, Guimarães e Simas (2005), a profissão de operador de checkout de supermercado é caracterizada por movimentos repetitivos e na maior parte do tempo há realização de movimentos alternados enquanto se está no posto de trabalho. Sendo assim, essas posturas assumidas podem estar influenciando e comprometendo o desempenho nas horas trabalhadas, gerando dor e/ou desconforto corporal.

Os problemas musculoesqueléticos desencadeados pelas situações ocupacionais são preocupantes, uma vez que levam a doenças e a repercussões negativas, tanto de ordem social quanto econômicas, para o Estado, empresas e indivíduos. Para a empresa, há redução no número de trabalhadores e de horas trabalhadas, o que provoca uma perda na produção e na qualidade do serviço; para o Estado, as despesas recaem sobre o Instituto Nacional do Seguro Social (INSS) e decorrem do pagamento de benefícios previdenciários, tratamento e reabilitação (DE LUCCA, ção das atividades, de forma a prevenir o aparecimento de sintomas musculoesqueléticos e dificuldades diversas no desenvolvimento da atividade, bem como auxiliar nos aspectos de produtividade e qualidade do serviço realizado.

\section{METODOLOGIA}

Este estudo caracteriza-se, segundo Thomas e Nelson (2002), como um estudo descritivo-exploratório, de corte transversal, no qual foi realizado um levantamento de informações ainda pouco investigadas em uma determinada população.

O estudo foi realizado com trabalhadores de uma loja de uma rede de supermercados localizada na cidade de Itajaí-SC, caracterizada por vendas tanto no varejo quanto no atacado. Na época do estudo, o corpo funcional desta loja era integrado por 168 trabalhadores, sendo 53 operadores de checkout. Do total, 48 concordaram em participar do estudo e responderam ao questionário nórdico dos sintomas musculoesqueléticos (KUORINKA et al., 1987) para identificação da presença das dores referidas pelos trabalhadores. Este instrumento foi adaptado culturalmente para a língua portuguesa por Barros e Alexandre (2003), apresentando uma confiabilidade que varia de 0,88 a 1 , segundo o coeficiente de Kappa, validado por Pinheiro, Tróccoli e Carvalho (2002) com um índice adequado de validade para a versão brasileira. 
Esse questionário (autoaplicado) apresenta uma figura humana vista de costas, dividida em regiões anatômicas: cervical, ombros, cotovelos, punhos/mãos, região superior das costas, região inferior das costas (lombar), quadril/ coxas, joelhos, tornozelos/pés. As questões relacionadas a cada área anatômica verificam a presença de dores nos últimos 12 meses e nos últimos sete dias. Além disso, esse instrumento investiga se os indivíduos ficaram impedidos de exercer suas atividades normais e se houve necessidade de impedimento das atividades profissionais. Considerandose a utilização do questionário nórdico como referencial teórico, optou-se por definir o autorrelato de dor, formigamento ou dormência nas nove diferentes regiões corporais citadas como sintomas osteomusculares (BARROS; ALEXANDRE, 2003).

Além deste instrumento, para a investigação dos fatores associados às queixas musculoesqueléticas foi elaborado um questionário multidimensional com perguntas abertas, em que constaram os itens relacionados aos aspectos sociodemográficos, de saúde e de condições de trabalho. Os aspectos sociodemográficos basearam-se nas questões de idade, gênero (feminino e masculino), estado civil (solteiro, casado, separado, viúvo) e grau de instrução $\left(2^{\circ}\right.$ grau incompleto, $2^{\circ}$ grau completo, $3^{\circ}$ grau incompleto e $3^{\circ}$ grau completo). Além da identificação das queixas musculoesqueléticas determinadas pelo questionário nórdico, a saúde foi relacionada ao hábito e à frequência na prática de exercícios físicos e ao uso de medicamentos para as queixas de dor. Para as investigações das condições de trabalho foi identificado o tempo de serviço na empresa, a realização de horas extras, a realização de pausas, outras atividades remuneradas e turnos de trabalho. Além disso, foi realizada a verificação das condições ergonômicas dos postos de trabalho dos checkouts a partir do cumprimento do Anexo I da NR-17 (portaria n. ${ }^{\circ}$ 8, de 30 de março de 2007 - DOU 02/04/2007) (BRASIL, 2007), como, por exemplo, disposição e qualidade do assento, posturas assumidas, terminais de vídeo, funcionamento das esteiras e interações diversas com os elementos do trabalho e pessoas. Para a coleta dessas informações foram realizadas observações livres in loco, mais entrevista e análise de documentos, como proposto por Guérin et al. (2001).

A aplicação dos instrumentos foi realizada em sessões individuais, nos locais de trabalho dos indivíduos, após autorização dos responsáveis e com a concordância dos trabalhadores, que foram informados sobre os objetivos do estudo.

Para a análise dos dados foi realizada a estatística descritiva por meio de média e desvio padrão para as variáveis contínuas, sendo que para as variáveis categóricas foi realizada a distribuição de frequência absoluta e relativa. Foi realizada análise de correlação de Spearman $(r h o)$ entre o gênero, a idade, o estado civil, o grau de instrução, o tempo de serviço, a realização de outro trabalho remunerado, as pausas, o uso de medicamentos e a prática de exercícios físicos. Para a determinação das correlações foi utilizado o critério adotado por Malina (1996), que descreve correlação baixa para um valor menor que 0,30 , moderada para valores entre 0,30 e 0,60 e alta para valores superiores a 0,60 .

Para testar a homogeneidade das proporções das queixas musculoesqueléticas (nos últimos 12 meses, sete dias e afastamento em função das queixas) com as variáveis sociodemográficas, de saúde e de condições de trabalho foram utilizados o teste Qui-Quadrado e o teste exato de Fisher. O nível de significância adotado para todos os testes foi de $5 \%$.

\section{RESULTADOS}

Dentre os resultados obtidos, a média de idade dos operadores de checkout foi de 25,94 $\pm 7,34$ anos, sendo $70,83 \%$ $(\mathrm{n}=34)$ mulheres e $29,17 \%(\mathrm{n}=14)$ homens. Considerando o estado civil, $62,50 \%(n=30)$ dos trabalhadores são solteiros, $31,25 \%(\mathrm{n}=15)$, casados e $6,25 \%(\mathrm{n}=3)$, separados. Quanto ao grau de instrução, $8 \%(\mathrm{n}=4)$ possuem $2 .^{\circ}$ grau incompleto, $79 \%(\mathrm{n}=38)$ possuem $2^{\circ}$ grau completo, $10 \%$ $(\mathrm{n}=5)$ possuem $3^{\circ}$ grau incompleto e $2 \%(\mathrm{n}=1)$ possuem $3^{\circ}$ grau completo. Dentre eles, apenas $4,18 \%(\mathrm{n}=2)$ apresentaram o desempenho de outra função remunerada.

O tempo de trabalho na empresa avaliada foi de no mínimo um mês e, no máximo, de 49 meses, sendo a média de $12,17 \pm 11,15$ meses. Somente na atividade de operador de checkout foram identificados 18 turnos diferenciados de trabalho, que se distinguem pelo horário de início e de término da jornada de trabalho, com distintos horários de pausas. Independentemente do turno é concedido um intervalo de 20 minutos para refeição (pausa obrigatória para seis horas de trabalho) a todos os trabalhadores e uma escala pré-definida para folgas. Embora a empresa não permita a realização de horas extras, identificou-se que a jornada de trabalho pode se estender durante o fechamento da loja e do caixa. Como o fechamento das vendas do caixa é acompanhado individualmente pelo supervisor, as pausas podem ser prejudicadas pelo movimento da loja (fluxo intenso de clientes em alguns períodos) e quando este esteja ocupado com outras atribuições.

A empresa avaliada conta com 24 postos de trabalhos (operadores de checkouts), sendo seis para caixas rápidos (checkout para poucos volumes ou cestinhas), um para atendimento a portadores de necessidades especiais (gestantes, idosos e outros) e dois para compras por atacado. 
Nos demais checkouts são preferencialmente comercializados produtos a varejo. Para o atendimento ao público, há revezamento dos trabalhadores em função dos checkouts de forma não sistematizada. As atividades dos operadores de checkout são executadas em postos de trabalho com esteira, com exceção dos caixas rápidos. Além disso, existe uma registradora, um gabinete para armazenamento de dinheiro (caixa), uma balança para pesagem de frutas, legumes ou verduras (F.L.V.), uma cadeira com encosto e regulagem (Figura 1). Além desses equipamentos, observa-se que há outros elementos como lixeiras, sacolas plásticas e computadores que são dispostos sob o checkout, para uso durante a atividade.

A postura assumida pelo operador durante a atividade nesse posto de trabalho se alterna entre sentada e em pé, podendo o trabalhador escolher a posição livremente, conforme a exigência de uso de força requerida para o registro do produto durante a compra. O registro é realizado mediante a leitura do código de barras existente em cada produto, que é posicionado em frente ao leitor. Por vezes, quando o código de barras não permite a correta leitura, o operador deve fazer a identificação, leitura e digitação do código do produto para registro e cobrança.

No que se refere às cadeiras, observou-se que apenas $17 \%(n=4)$ delas se encontravam em bom estado de funcionamento, ou seja, ao menos com todas as regulagens funcionais e nenhuma parte quebrada. Porém, o número de cadeiras danificadas por checkout é significativamente superior, totalizando $63 \%(n=15)$ e não foram encontradas cadeiras em um total de cinco checkouts, o que corresponde a $21 \%$. De todas as cadeiras, duas não possuíam encosto para apoio das costas do trabalhador.

No que se refere à esteira mecânica, $28 \%(\mathrm{n}=5)$ dos 18 checkouts com esteira não estavam em funcionamento por problemas de manutenção. Além disso, houve queixas e relatos de acidentes de natureza elétrica, ainda em fase de monitoramento. Destaca-se aqui que a manutenção desses

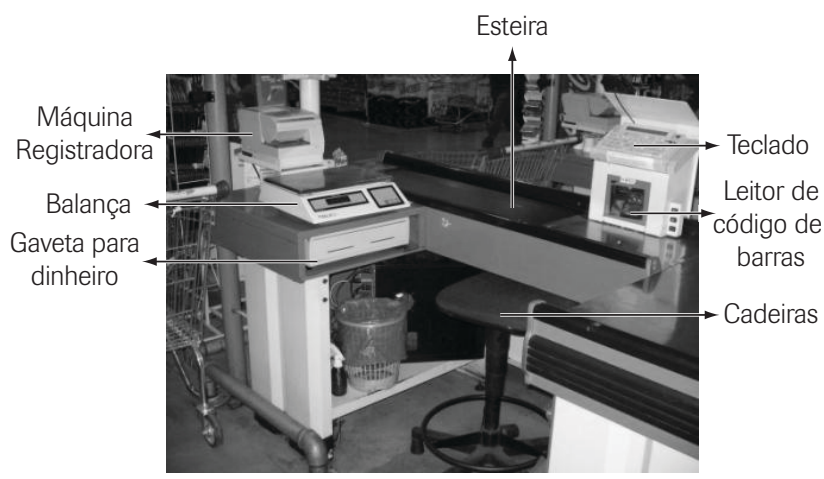

Figura 1: Posto de trabalho - checkout. equipamentos é realizada pelo técnico de manutenção de outro estabelecimento dessa rede de supermercados, o que pode comprometer e até inviabilizar um atendimento mais eficiente. Também foi identificado que $11 \%(n=2)$ das esteiras apresentavam problemas durante o funcionamento, que somadas àquelas sem funcionamento totalizam 39\% $(\mathrm{n}=7)$.

Com relação às balanças, foi identificado que $21 \%$ $(n=5)$ estavam posicionadas do lado esquerdo do operador e $79 \%(\mathrm{n}=19)$ à direita, todas em altura superior às esteiras (perpendicularmente e $12 \mathrm{~cm}$ mais altas que a superfície do checkout).

Quanto às questões de saúde, a prática de exercícios físicos é realizada por $31,25 \%(\mathrm{n}=15)$ dos trabalhadores. Nenhuma das modalidades realizadas, porém, é desenvolvida dentro da empresa, uma vez que a mesma não possui programas para a prática de exercícios ou ginástica laboral. As atividades realizadas, segundo a resposta dos trabalhadores foram: caminhada (53\%; $\mathrm{n}=8)$, andar de bicicleta $(13 \% ; \mathrm{n}=2)$; musculação $(7 \% ; \mathrm{n}=1)$ e outras informadas $(27 \% ; n=4)$. Em relação à frequência durante a semana, $40 \%(\mathrm{n}=6)$ informaram praticar exercício físico 7 vezes, $7 \%(\mathrm{n}=1), 5$ vezes, $13 \%(\mathrm{n}=2), 3$ vezes, $7 \%(\mathrm{n}=1)$, 2 vezes, $7 \%(n=1), 1$ vez por semana e $27 \%(n=4)$ não informaram. Investigando a utilização de medicamentos frente às queixas musculoesqueléticas, foi observado que $60,42 \%(n=29)$ fizeram ou faziam uso de algum tipo de medicamento.

De acordo com os resultados do questionário nórdico, $89,58 \%(n=43)$ dos trabalhadores referiram algum tipo de sintoma musculoesquelético nos últimos 12 meses, $41,67 \%(\mathrm{n}=20)$ relataram ter necessidade de afastamento das atividades exercidas no supermercado em função da dor/desconforto. Ainda, 77,08\% ( $\mathrm{n}=37)$ dos entrevistados referiram que nos últimos sete dias haviam sentido dor/desconforto em pelo menos uma das diferentes regiões corporais.

As prevalências dessas queixas foram na região superior das costas $(65 \% ; \mathrm{n}=31)$ considerando os últimos 12 meses, assim como nos últimos sete dias de trabalho (com prevalências de $54 \%$ dos trabalhadores; $\mathrm{n}=26$ ). Os afastamentos confirmam as queixas relatadas ao longo do tempo, sendo estes motivados pelas queixas na região superior das costas (27\%; $\mathrm{n}=13)$. Os sintomas musculoesqueléticos de dor/ desconforto referidos pelos operadores de checkout nas diferentes regiões corporais nos últimos 12 meses e nos últimos sete dias, mais a ocorrêmcia de afastamentos das atividades de trabalho devido a essa condição podem ser observados na Tabela 1.

Considerando uma análise mais detalhada, não foi possível observar predominância dos sintomas musculoesqueléticos em relação aos membros. Para os ombros, as queixas 
Tabela 1: Sintomas musculoesqueléticos de dor/ desconforto referidos pelos operadores de checkout nas diferentes regiões corporais nos últimos

12 meses e nos últimos sete dias, mais a porcentagem de afastamentos das atividades de trabalho em função dessa condição.

\begin{tabular}{lccc}
\hline Regiões corporais & 12 meses (\%) & Afastamentos (\%) & 7 dias (\%) \\
\hline Pescoço & 33 & 8 & 25 \\
Ombros & 29 & 10 & 38 \\
Cotovelos & 4 & 0 & 0 \\
Punhos & 15 & 10 & 19 \\
Costas - superior & 65 & 27 & 54 \\
Costas - inferior & 44 & 17 & 35 \\
Quadril/coxas & 6 & 0 & 4 \\
Joelhos & 19 & 2 & 6 \\
Tornozelos & 23 & 4 & 10 \\
\hline
\end{tabular}

foram predominantes no lado direito $(14,58 \% ; n=7)$, enquanto nos punhos houve uma predominância contrária, ou seja, $18,75 \%(n=9)$ relataram queixas no lado esquerdo. $\mathrm{Na}$ região dos cotovelos, as queixas, quando mencionadas, foram indicadas em ambos os membros.

As associações das variáveis sociodemográficas de saúde e de condição de trabalho e os sintomas musculoesqueléticos nos últimos 12 meses e últimos sete dias, mais os afastamentos em função dessas queixas estão ilustrados na Tabela 2.

De acordo com os resultados ilustrados na Tabela 2, podem-se observar diferenças estatisticamente significativas relacionando o uso de medicamentos e os afastamentos do trabalho em função das queixas nos últimos 12 meses.

As correlações entre as queixas nas diferentes regiões corporais (nos últimos 12 meses e nos últimos sete dias) mais os afastamentos, com as variáveis: gênero, estado civil,

Tabela 2: Associações entre os sintomas musculoesqueléticos nos últimos 12 meses, sete dias e os afastamentos em função das queixas e as variáveis sociodemográficas (gênero, idade, estado civil e grau de instrução), de saúde (uso de medicamentos e prática de exercícios físicos) e de condições de trabalho (tempo de serviço, outro trabalho remunerado e pausas).

\begin{tabular}{|c|c|c|c|c|c|c|c|c|c|}
\hline \multirow[t]{3}{*}{ Variáveis } & \multicolumn{9}{|c|}{ Presença de queixas musculoesqueléticas } \\
\hline & \multicolumn{3}{|c|}{12 meses } & \multicolumn{3}{|c|}{ afastamentos } & \multicolumn{3}{|c|}{7 dias } \\
\hline & $\mathrm{n}$ & $\%$ & $\mathrm{p}^{*}$ & $\mathrm{n}$ & $\%$ & $\mathrm{p}^{*}$ & $\mathrm{n}$ & $\%$ & $\mathrm{p}^{*}$ \\
\hline \multicolumn{10}{|l|}{ Gênero } \\
\hline Masculino & 11 & 25,58 & \multirow{2}{*}{0,109} & 3 & 15,00 & \multirow{2}{*}{0,068} & 10 & 27,03 & \multirow{2}{*}{0,550} \\
\hline Feminino & 32 & 74,42 & & 17 & 85,00 & & 27 & 72,97 & \\
\hline \multicolumn{10}{|l|}{ Idade } \\
\hline Até 24 anos & 21 & 48,84 & \multirow{2}{*}{0,541} & 11 & 55,00 & \multirow{2}{*}{0,296} & 17 & 45,95 & \multirow{2}{*}{0,437} \\
\hline A partir dos 25 anos & 22 & 51,16 & & 9 & 45,00 & & 20 & 54,05 & \\
\hline \multicolumn{10}{|l|}{ Estado civil } \\
\hline Solteiro & 26 & 60,47 & \multirow{3}{*}{0,654} & 11 & 55,00 & \multirow{3}{*}{0,104} & 23 & 62,16 & \multirow{3}{*}{0,878} \\
\hline Casado & 14 & 32,56 & & 9 & 45,00 & & 12 & 32,43 & \\
\hline Separado & 3 & 6,98 & & 0 & 0,00 & & 2 & 5,41 & \\
\hline \multicolumn{10}{|l|}{ Grau de instrução } \\
\hline $2^{\circ}$ grau incompleto & 4 & 9,30 & \multirow{4}{*}{0,137} & 2 & 10,00 & \multirow{4}{*}{0,585} & 2 & 5,41 & \multirow{4}{*}{0,086} \\
\hline $2^{\circ}$ grau completo & 35 & 81,40 & & 17 & 85,00 & & 30 & 81,08 & \\
\hline $3^{\circ}$ grau incompleto & 3 & 6,98 & & 1 & 5,00 & & 5 & 13,51 & \\
\hline $3^{\circ}$ grau completo & 1 & 2,33 & & 0 & 0,00 & & 0 & 0,00 & \\
\hline \multicolumn{10}{|l|}{ Tempo de serviço } \\
\hline Até 10 meses & 24 & 55,81 & \multirow{3}{*}{0,161} & 9 & 45,00 & \multirow{3}{*}{0,139} & 22 & 59,46 & \multirow{3}{*}{0,963} \\
\hline De 11 a 20 meses & 10 & 23,26 & & 5 & 25,00 & & 8 & 21,62 & \\
\hline A partir de 21 meses & 9 & 20,93 & & 6 & 30,00 & & 7 & 18,92 & \\
\hline \multicolumn{10}{|l|}{ Outro trabalho remunerado } \\
\hline Sim & 42 & 97,67 & \multirow{2}{*}{0,199} & 19 & 95,00 & 0665 & 35 & 94,59 & (590 \\
\hline Não & 1 & 2,33 & & 1 & 5,00 & 0,000 & 2 & 5,41 & 0,090 \\
\hline Pausas & & & & & & & & & \\
\hline Sem pausas & 4 & 9,30 & & 2 & 10,00 & & 2 & 5,41 & \\
\hline Lanche e refeição & 28 & 65,12 & 0,281 & 12 & 60,00 & 0,536 & 26 & 70,27 & 0,396 \\
\hline Refeição e lanche & 11 & 25,58 & & 6 & 30,00 & & 9 & 24,32 & \\
\hline Uso de medicamentos & & & & & & & & & \\
\hline Sim & 29 & 67,44 & (0)7 & 18 & 90,00 & $<0 \cap 01$ & 25 & 67,57 & 0067 \\
\hline Não & 14 & 32,56 & 0,007 & 2 & 10,00 & ( & 12 & 32,43 & 0,007 \\
\hline Prática de exercícios físicc & & & & & & & & & \\
\hline Sim & 14 & 32,56 & 0.497 & 7 & 35,00 & 0.435 & 11 & 29,73 & 0.471 \\
\hline Não & 29 & 67,44 & 0,497 & 13 & 65,00 & 0,400 & 26 & 70,27 & 0,471 \\
\hline
\end{tabular}

*Valor menor que 0,05 indica diferença estatisticamente significativa. 
tempo de serviço, outro trabalho remunerado, pausas e uso de medicamentos estão ilustradas na Tabela 3.

De acordo com os resultados encontrados na Tabela 3, a maioria das associações é considerada moderada conforme indicações de Malina (1996). A correlação mais alta encontrada foi relacionada aos afastamentos por queixas nos joelhos e aos trabalhadores que exerceram outro tipo de função remunerada além das atividades na empresa. As variáveis turno, idade e prática de exercícios físicos não apresentaram correlações significativas com as queixas em nenhuma das regiões corporais.

\section{DISCUSSÃO}

Para Souza (2007), no caso do processo de prestação de serviços em um checkout de supermercado, estão envolvidos os operadores e os clientes que estão finalizando as suas compras e exigindo um bom atendimento. É ali que são evidenciadas as disfunções do sistema de trabalho, como preços com marcação diferente do anunciado, sistema de cobrança lento, falta de troco e outros. Por sua vez, essas disfunções podem repercutir em reclamações dos clientes junto aos trabalhadores, que não possuem o controle do funcionamento total das atividades anteriores à sua.

Alguns estudos estão sendo realizados com o objetivo de identificar posturas corporais consideradas críticas e que se relacionem com as queixas identificadas nos operadores de checkout. Para Teixeira et al. (2008), os sintomas musculoesqueléticos apresentados pelos operadores de cai$\mathrm{xa}$ (checkout) podem estar relacionados a alguns aspectos peculiares encontrados nos postos de trabalho. As inconformidades com o Anexo 1 da NR-17, principalmente em

Tabela 3: Correlações entre as queixas nas diferentes regiões corporais (nos últimos 12 meses e nos últimos sete dias) mais os afastamentos, com as variáveis: gênero, estado civil, tempo de serviço, outro trabalho remunerado, pausas e uso de medicamentos.

\begin{tabular}{|c|c|c|c|c|c|c|c|}
\hline & Variáveis & Gênero & Estado civil & Tempo de serviço & $\begin{array}{c}\text { Outro trabalho } \\
\text { remunerado }\end{array}$ & Pausas & $\begin{array}{c}\text { Uso de } \\
\text { medicamento }\end{array}$ \\
\hline \multirow{15}{*}{ 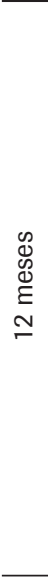 } & Pescoço & & & & & & \\
\hline & $r$ & 0,032 & $-0,084$ & 0,095 & $-0,074$ & $-0,139$ & 0,301 \\
\hline & $\mathrm{p}^{*}$ & 0,827 & 0,569 & 0,521 & 0,619 & 0,346 & 0,037 \\
\hline & Ombro esq & & & & & & \\
\hline & $\mathrm{r}$ & 0,213 & $-0,295$ & 0,064 & 0,054 & 0,080 & 0,033 \\
\hline & $\mathrm{p}^{*}$ & 0,146 & 0,041 & 0,666 & 0,716 & 0,588 & 0,824 \\
\hline & Região sup & & & & & & \\
\hline & $r$ & $-0,100$ & $-0,116$ & $-0,162$ & 0,064 & 0,025 & 0,380 \\
\hline & $\mathrm{p}^{*}$ & 0,500 & 0,431 & 0,272 & 0,668 & 0,865 & 0,008 \\
\hline & Região infe & & & & & & \\
\hline & $r$ & $-0,196$ & $-0,080$ & $-0,049$ & $-0,026$ & $-0,395$ & 0,199 \\
\hline & $\mathrm{p}^{*}$ & 0,181 & 0,588 & 0,743 & 0,859 & 0,005 & 0,176 \\
\hline & Joelhos & & & & & & \\
\hline & $\mathrm{r}$ & $-0,308$ & $-0,081$ & $-0,093$ & $-0,167$ & $-0,076$ & 0,171 \\
\hline & $\mathrm{p}^{*}$ & 0,033 & 0,582 & 0,532 & 0,257 & 0,609 & 0,246 \\
\hline \multirow{9}{*}{ 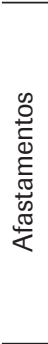 } & Região sup & & & & & & \\
\hline & $r$ & $-0,082$ & 0,107 & $-0,161$ & 0,127 & $-0,191$ & 0,302 \\
\hline & $\mathrm{p}^{*}$ & 0,581 & 0,468 & 0,275 & 0,389 & 0,193 & 0,037 \\
\hline & Joelhos & & & & & & \\
\hline & $r$ & $-0,094$ & $-0,167$ & $-0,235$ & $-0,700$ & $-0,239$ & 0,118 \\
\hline & $\mathrm{p}^{*}$ & 0,527 & 0,257 & 0,108 & $<0,001$ & 0,101 & 0,424 \\
\hline & Tornozelos & & & & & & \\
\hline & $r$ & $-0,134$ & $-0,239$ & $-0,336$ & $-0,478$ & $-0,139$ & 0,169 \\
\hline & $\mathrm{p}^{*}$ & 0,365 & 0,102 & 0,020 & 0,001 & 0,347 & 0,251 \\
\hline \multirow{6}{*}{$\begin{array}{l}\frac{\pi}{\pi} \\
\frac{\pi}{0} \\
N\end{array}$} & Pescoço & & & & & & \\
\hline & $r$ & 0,053 & 0,073 & $-0,125$ & $-0,120$ & $-0,384$ & 0,172 \\
\hline & $\mathrm{p}^{*}$ & 0,721 & 0,620 & 0,397 & 0,415 & 0,007 & 0,242 \\
\hline & Punhos & & & & & & \\
\hline & $\mathrm{r}$ & $-0,191$ & 0,020 & 0,077 & 0,100 & 0,133 & 0,389 \\
\hline & $\mathrm{p}^{*}$ & 0,194 & 0,891 & 0,602 & 0,498 & 0,369 & 0,006 \\
\hline
\end{tabular}

* Valor de probabilidade de significância (p -valor). 
relação a disposição dos postos de trabalho (no que tange à balança) e com relação ao estado de conservação dos equipamentos (principalmente cadeiras e esteiras) parecem estar influenciando a integridade física dos trabalhadores. Esta afirmação não está relacionada apenas à alta incidência de queixas musculoesqueléticas (Tabela 1), mas também às associações e correlações encontradas, que indicam que o sistema de trabalho relaciona-se aos sintomas de dor/ desconforto relatados pelos trabalhadores.

O estudo das condições de trabalho previsto no Anexo 1 da NR-17 visando a transformação do trabalho parece permitir a identificação de alternativas que preservem a integridade física dos trabalhadores e a manutenção da qualidade de vida deles, sem desconsiderar os aspectos de produtividade e qualidade. Essas alternativas estão relacionadas especialmente às características e configuração dos postos de trabalho, algumas delas discutidas aqui. No caso do supermercado estudado, os postos de trabalho não apresentam possibilidades de ajustes, o que, frente às características antropométricas diferenciadas de cada operador, leva à ne-
Como essas orientações e indicações da norma não foram analisadas no presente estudo, as queixas musculoesqueléticas podem estar associadas a essas inconformidades, principalmente as relacionadas à região das costas. Outra relação importante poderia estar ligada ao aparecimento de problemas nos membros inferiores (joelhos e tornozelos), uma vez que a predominância da postura em pé (pela falta de cadeiras ou por elas não apresentarem condições adequadas de uso) leva à sobrecarga nestas articulações. No caso dos tornozelos, o tempo de serviço se mostrou associado com a presença de queixas na região do tornozelo (Tabela 3), e o exercício de outro trabalho remunerado, com os problemas na região dos membros inferiores (tornozelo e joelhos) (Tabela 3 ).

Além disso, a alternância de posições, encontrada em 92\% dos trabalhadores do estudo realizado por Battisti, Guimarães e Simas (2005), fica inviável ou tem sua adoção limitada na prática dos operadores de checkout avaliados, uma vez que eles parecem adotar posturas inadequadas devido às inconformidades dos postos de trabalho.

Outra problema foi encontrado na utilização da balança para pesagem dos produtos, como ilustra a Figura 1. Segundo o Anexo I da NR-17, essa balança deve estar instalada frontalmente ao trabalhador, nivelada pelo checkout. A balança não deve estar posicionada ao lado do operador para que ele não tenha que realizar rotação do tronco

cessidade de utilização de recursos para ajustes individuais. Segundo Trelha et al. (2007), os operadores exercem suas funções em postos de trabalho que possuem design com medidas e formatos padronizados e que, portanto, não levam em consideração as diferenças antropométricas individuais. Porém, segundo a NR-17, as dimensões devem atender 90\% das características antropométricas individuais dos trabalhadores (BRASIL, 2007). Atender a essas indicações da norma é importante, esse atendimento pode refletir positivamente sobre a rotatividade apresentada pelos trabalhadores da empresa avaliada, visto que o tempo de serviço na empresa é relativamente pequeno (TEIXEIRA et al., 2008).

Essas considerações agravam-se com os achados do presente estudo, que registrou $63 \%(n=15)$ de cadeiras danificadas, sem encostos ou com encostos inexistentes. Além disso, o apoio para os pés também é uma providência importante de ser adotada, pois este permite a flexibilidade de ajuste individual (IIDA, 2005; KROEMER; GRANDJEAN, 2005). Segundo os mesmos autores, os pés devidamente apoiados oferecem o necessário suporte para a coluna, evitando o aparecimento de dor/desconforto nos membros inferiores e região inferior das costas. durante a pesagem. Além disso, o desnível da balança em relação ao checkout (acima deste) leva o operador a realizar repetidos levantamentos dos produtos que exigem pesagem - e isso muitas vezes ocorre com o uso de apenas um dos membros superiores (normalmente aquele posicionado ao lado da balança). Quando faz com que movimentos contraindicados sejam realizados para o bom desenvolvimento da atividade, o posto de trabalho pode, consequentemente, estar inflacionando o número de queixas de dor/desconforto, principalmente na região das costas.

Com relação às queixas, estas parecem prevalentemente relacionar-se aos membros superiores, como indicam Melo Júnior e Rodrigues (2005), que observaram as maiores incidências de relatos de dor na região dos ombros $(24,48 \%)$ e pescoço $(22,46 \%)$. No presente estudo, as reclamações envolveram principalmente a região superior das costas, seguidas da região inferior das costas, o pescoço e os ombros, tanto nos últimos 12 meses quanto nos últimos sete dias (Tabela 1). Essas prevalências também foram observadas nos afastamentos em função das queixas. Estes achados são confirmados pelo estudo de Trelha et al. (2007), que encontrou $35 \%$ dos trabalhadores que operavam caixas afastados 
do trabalho em função dos acometimentos musculoesqueléticos. Estes resultados corroboram e exemplificam a necessidade de estudos e intervenções ergonômicas como previsto no Anexo 1 da NR17 (TEIXEIRA et al., 2008).

Para Rodacki et al. (2006), há diferentes angulações de tronco, nos planos sagital e frontal, dependendo do produto (peso) que é manipulado que pode, por exemplo, variar daqueles com $0,2 \mathrm{~kg}$ àqueles com $5 \mathrm{~kg}$. Essas condições podem se agravar se o alcance manual e visual é dificultado pela impossibilidade de uso das esteiras. Além disso, segundo Picoloto e Silveira (2008), a musculatura das costas é a que mais sofre com o levantamento de peso, pois, ao levantar um peso com as mãos, o esforço transfere-se para a coluna vertebral. Para Iida (2005), a estrutura da coluna vertebral, composta de discos superpostos, pode ser capaz de suportar cargas no sentido vertical, porém essas estruturas são mais frágeis quando as forças não apresentam a mesma direção do seu eixo, como é o caso da manipulação dos produtos no checkout.

Para Trelha et al. (2007), os movimentos e as posturas durante o período de trabalho, associados à inadequação do posto, favorecem a sobrecarga das estruturas musculoesqueléticas. Este fato em parte justifica a pre-

\section{I ma das atitudes encontradas entre os trabalhadores para lidar com a dor é o uso de medicamentos.}

disposição dos trabalhadores avaliados aos sintomas musculoesqueléticos.

Também o ensacamento de mercadorias deve ser evitado no ciclo de trabalho do operador de checkout, mantendo-se no mínimo um ensacador para cada três caixas em funcionamento (BRASIL, 2007). Como a empresa pesquisada não disponibilizava esse tipo de serviço, operador e cliente dividiam a responsabilidade pelo empacotamento das mercadorias o que, consequentemente, sempre leva a um aumento da carga física.

Rodacki et al. (2006) indicaram que, devido ao significativo número de ciclos de movimentos realizados durante o dia, mesmo que o operador de checkout manipule produtos leves, pode haver risco para a coluna. Nesse sentido, Harber et al. (1992) demonstraram que esse profissional executa aproximadamente 1.442 movimentos do membro superior dominante por hora. De forma geral, para Rodacki et al. (2006), não são só as estruturas da coluna que esse trabalho pode acometer, esses e outros prejuízos já foram identificados em outros estudos (LEHMAN; PSIHOGIOS; MEULENBROEK, 2001; MELO JÚNIOR; RODRIGUES, 2005; TRELHA et al., 2007).
Para Battisti, Guimarães e Simas (2005), 95\% dos operadores de checkout de supermercado julgam estar realizando movimentos repetitivos, sendo que o foco desses movimentos está no momento de passar as compras pela máquina de leitora ótica. Somado a isso, Picoloto e Silveira (2008) enfatizam que são fatores de surgimento de lesões nas regiões dos membros superiores o trabalhar sem apoio, de forma repetitiva e que demanda força para a manipulação de objetos. Porém, no presente estudo, as queixas na região do cotovelo e punhos não se mostraram tão prevalentes quando comparadas a outras regiões (Tabela 1).

No estudo de Melo Junior e Rodrigues (2005), 77,27\% dos operadores de checkout declararam apresentar dor durante a jornada e $22,73 \%$ declaram não senti-la. Neste estudo, somente $10,42 \%(\mathrm{n}=5)$ dos indivíduos que participaram do levantamento de dados não apresentaram queixas de dor/desconforto relacionadas aos últimos 12 meses, enquanto nos últimos sete dias o percentual de queixosos foi de $22,92 \%(n=11)$. Além disso, dentre os 48 operadores analisados, 58,33\% $(\mathrm{n}=28)$ não necessitaram se afastar das atividades em função das queixas.

Diante disso, uma das atitudes encontradas entre os trabalhadores para lidar com a dor é o uso de medicamentos (OLIVEIRA, 2000; KEOGH; MCCRACKEN; ECCLESTON, 2005; SILVA, 2007). Como indicado na Tabela 2, os trabalhadores que fazem uso dessa estratégia são os que relatam mais queixas e possuem maiores percentuais de afastamento. Sob o efeito de medicação, os indivíduos não sentem o sintoma e, consequentemente, a lesão durante a atividade fica assintomática (SOUZA; ALMEIDA, 2006), o que pode provocar o agravamento do problema.

As alternativas para os problemas musculoesqueléticos estariam relacionadas a medidas de prevenção, como prática de exercícios físicos e de pausas sistemáticas, adequação do mobiliário e dos instrumentos de trabalho e outras que, de forma integrada, visem o conforto, o bem-estar e a eficácia no trabalho. No caso da prática de exercícios físicos, Maciel, Fernandes e Medeiros (2006) observaram que a maioria dos sedentários apresentava queixas de dor, enquanto que menos da metade dos trabalhadores praticantes de algum tipo de exercício físico relataram essa sintomatologia. Os autores ainda enfatizam os benefícios de se manter um estilo de vida fisicamente ativo, citando as adaptações circulatórias, metabólicas e osteomusculares. Por sua vez, mesmo com essas evidências, a empresa avaliada não possui nem disponibiliza programa de incentivo à prática de atividades físicas, sendo estas realizadas nos momentos de lazer dos trabalhadores. 
No estudo de Trelha et al. (2007), que avaliou um supermercado de grande porte na região de Londrina/PR, não foi identificada pausa regular durante a jornada de trabalho, sendo o descanso realizado apenas no horário destinado ao almoço. Para Batista (2007), as pausas são necessárias para garantir a recuperação física de um processo de fadiga muscular orgânica e de microtraumas em estruturas como tendões, bainhas e bolsas sinoviais. Neste trabalho, observou-se que os operadores de caixa (do turno vespertino e noturno) contam com uma pausa para lanche, enquanto aqueles do turno matutino fazem o lanche antes do início das suas atividades, o que demonstra que eles também não realizam as pausas sistemáticas indicadas para o descanso.

Outra importante ação a ser adotada pelos supermercados se refere ao treinamento, que segundo o Anexo I da NR-17 visa "aumentar o conhecimento da relação entre o trabalho e a promoção da saúde" desses profissionais (BRASIL, 2007), abordando, no mínimo: a) posto de trabalho; b) manipulação de mercadorias; c) organização do trabalho; d) aspectos psicossociais do trabalho; e) agravos à saúde mais encontrados entre operadores de checkout. Na empresa avaliada, o treinamento é um item que pode ser melhorado, o que pode contribuir para o conhecimento dos riscos relacionados à realização das atividades (físicas, ambientais ou organizacionais), das posturas ideais a serem adotadas durante a jornada de trabalho ou de possíveis atitudes preventivas, em prol de um trabalho mais seguro e de qualidade. É válido ressaltar que a redação da norma estabelece que "cada trabalhador deve receber treinamento com duração mínima de duas horas até o trigésimo dia da data da sua admissão, com reciclagem anual e com duração mínima de duas horas, ministrado durante sua jornada de trabalho" (BRASIL, 2007). Fica a critério de cada empresa a forma de colocar essa norma em prática.

No estudo de Guimarães (2005), os afastamentos do trabalho concentraram-se nas categorias de trabalhadores com menor grau de instrução, sendo que os trabalhadores que possuem o $3 .^{\circ}$ grau os que apresentam os menores índices de absenteísmo. No presente estudo, essas relações não foram identificadas, mas as instruções específicas para o trabalho podem ser estratégias positivas, incentivando a adoção de posturas corporais corretas e atitudes sadias ante as atividades, contribuindo assim para a diminuição das queixas e dos sintomas musculoesqueléticos.

Ademais, a tabela 3 ilustra que há associações entre o gênero, o estado civil, o tempo de serviço, o engajamento em outra atividade remunerada, a realização de pausas, o uso de medicamentos e as queixas de dor nas diferentes regiões corporais.
Com relação ao gênero, Salim (2003) e Picoloto e Silveira (2008) indicam que portadores de lesões por esforços repetitivos ou doenças osteomusculares relacionadas ao trabalho são em sua maioria mulheres. Para Costa et al. (2004), as mulheres em muitos casos exercem suas funções em condições ambientais e de saúde precárias, executando trabalhos repetitivos e penosos, o que constitui um grave quadro de desigualdade social pela sua condição sexual e as expõe a doenças do trabalho. No caso deste estudo, as mulheres constituem a maioria dos operadores de checkout $(70,83 \% ; \mathrm{n}=10) \mathrm{e}$, mesmo não havendo diferença de queixas musculoesqueléticas entre os gêneros (Tabela 2), parece que houve associação de forma positiva com a dor percebida pelos trabalhadores, de maneira que as mulheres tendem a sentir mais dores que os homens no que tange à região dos joelhos (Tabela 3 ).

\section{gênero se associou de forma positiva com a dor pelos trabalhadores.}

O estado civil também foi uma das variáveis que mostraram associação com o ombro esquerdo. Mesmo que o fato de ter filhos represente um dos principais causadores de queixas de dor nos membros superiores (ANDERSEN; GAARBOE, 1993), estas afirmações não podem ser feitas no presente estudo, uma vez que o número de filhos não foi investigado. As associações, porém, manifestaram-se no sentido dos indivíduos separados, seguidos pelos casados, todos apresentando maior tendência a apresentar queixas, o que indica necessidade de maiores investigações em futuros estudos.

Maciel, Fernandes e Medeiros (2006) encontraram relações interessantes envolvendo indivíduos que trabalhavam há mais de seis meses na mesma ocupação. Para os autores, esses trabalhadores apresentaram cerca de três vezes mais chances de desenvolver sintomatologias dolorosas em mais de uma região corporal. No caso do presente estudo, essas relações não foram encontradas e podem estar relacionadas à rotatividade dos trabalhadores na empresa, uma vez que o tempo médio de serviço encontrado foi de $12,17 \pm 11,15$ meses.

\section{CONCLUSÃO}

Com este estudo conclui-se que um número prevalente de operadores de checkout da empresa avaliada relatou dor/desconforto no trabalho, principalmente nos últimos 12 meses. As regiões mais acometidas foram as costas, 
seguidas pelo ombro e pescoço. As queixas impediram os trabalhadores de exercerem suas atividades principalmente em virtude das reclamações na região superior das costas.

No que se refere ao cumprimento da legislação vigente (Anexo I da NR-17), os postos de trabalho apresentavam possibilidades potenciais de serem melhorados, em especial no que se referia às balanças, cadeiras e funcionamento dos dispositivos, que podem estar contribuindo para o aparecimento de dor/desconforto. Além disso, conforme o Anexo I da NR-17, as obrigações previstas passam a ser exigidas depois de encerrados prazos de 90 dias, 180 dias, um ano da promulgação da norma, ou, ainda, para todas as lojas novas ou que forem submetidas a reformas até janeiro de 2008, para 15\% das lojas, até julho de 2009, para $35 \%$ das lojas, até dezembro de 2009 , para $65 \%$ das lojas, até dezembro de 2010 e, até dezembro de 2011, todas as lojas deverão estar conforme as indicações do Anexo I da NR-17 (BRASIL, 2007). Nesse sentido, recomenda-se, ainda, o estímulo à participação e ao envolvimento dos trabalhadores na promoção da adequação das condições de trabalho, especialmente no que se refere a mobiliário, turnos e pausas.

Ainda, quanto às variáveis sociodemográficas de saúde e de condições de trabalho investigadas, constatou-se que os trabalhadores que fazem uso de medicamentos são mais acometidos por queixas de dor nos últimos 12 meses e foram os que mais se afastaram das atividades de trabalho devido a queixas musculoesqueléticas em relação àqueles que não apresentaram acometimentos.

Por fim, a contribuição da ergonomia, mediante o estudo do trabalho no âmbito da engenharia de produção, permite propor ainda ações afetas tanto à organização do trabalho quanto à otimização dos sistemas produtivos. Nesse sentido, deve-se visar especialmente o cumprimento das normas legais vigentes, que possibilitam benefícios tanto para os trabalhadores - pela prevenção dos acometimentos decorrentes do trabalho -, quanto para a empresa - na medida em que se pode oportunizar o aumento da produtividade, da eficiência e da qualidade dos serviços.

\section{Artigo recebido em 06/02/2009 Aprovado para publicação em 28/06/2009}

\section{REFERÊNCIAS}

ANDERSEN, J. H.; GAARBOE, O. Prevalence of persistent neck and upper limb pain in a historical cohort of sewing machine operators. American Journal of Industrial Medicine, v. 24, n. 6, p. 677-687, 1993.

BARROS E. N. C.; ALEXANDRE, N. M. C. Cross-cultural adaptation of the Nordic musculoskeletal questionnaire. International Nursing Review, v. 50, n. 2, p. 101-108, 2003.

BRASIL. Portaria $n^{\circ} 8$, de 30 de março de 2007. Trabalho dos operadores de checkout. Disponível em: http://www.trt02.gov.br/geral/ tribunal2/legis/CLT/NRs/NR_17.html. Acesso em: 10 abril 2008. (DOU 02/04/2007).

CANDEIAS, N. M. F. Conceitos de educação e de promoção em saúde: mudanças individuais e mudanças organizacionais. Revista de Saúde Pública, v. 31, n. 2, p. 209-13, 1997.

COSTA, A. A. et al. Reconfiguração das relações de gênero no trabalho. São Paulo: CUT Brasil, 2004. 144 p.
De LUCCA, S. R. Os acidentes do trabalho no Brasil - algumas implicações de ordem econômica, social e legal. Revista Brasileira de Saúde Ocupacional, v. 22, n. 81, p. 7-14, 1994.

De VITTA, A.; BERTAGLIA, R. S.; PADOVANI, C. $R$. Efeitos de dois procedimentos educacionais sobre os sintomas musculoesqueléticos em trabalhadores administrativos. Revista Brasileira de Fisioterapia, v. 12, n. 1, p. 20-5, 2008.

GUÉRIN, F. et al. Compreender o trabalho para transformá-lo: a prática da ergonomia. São Paulo: Edgard Blücher: Fundação Vanzolini, 2001. 224 p.

GUIMARÃES, R. S. O. O absenteísmo entre os servidores civis de um hospital militar. Rio de Janeiro, 2005. 83 p. Dissertação (Mestrado em Saúde Pública) - Escola Nacional de Saúde Pública, FIOCRUZ.

HARBER, P. et al. The ergonomic challenge of repetitive motion with varying ergonomics stresses: characterizing supermarket checking work. American College of Occupational and Environmental Medicine, v. 34, n. 5, p. 518-527, 1992.

IIDA, I. Ergonomia: projeto e produção. 2 ed rev. ampl. São Paulo: Edgard Blucher, 2005. $630 \mathrm{p}$.

KEOGH, E.; McCRACKEN, L. M.; ECCLESTON, C. Gender moderates the association between depression and disability in chronic pain patients. European Journal of Pain, v. 10, n. 5, p. 413-422, 2006.

KUORINKA, I. et al. Standardised Nordic Questionnaires for the Analysis of Musculoskeletal Symptoms. Applied Ergonomics, v. 18, n. 3, p. 233-37, 1987.

KROEMER, K. H. E.; GRANDJEAN, E. Manual de Ergonomia: adaptando o trabalho ao homem. 5 ed. Porto Alegre: Bookman, 2005. 327 p.

LEHMAN, K. R.; PSIHOGIOS, J. P.; MEULENBROEK, R. J. G. Effects of sitting 
versus standing and scanner type on cashiers. Ergonomics, v. 7, n. 44, p. 719-738, 2001.

MACIEL, A. C. C.; FERNANDES, M. B.; MEDEIROS, L. S. Prevalência e fatores associados à sintomatologia dolorosa entre profissionais da indústria têxtil. Revista Brasileira de Epidemiologia, v. 9, n. 1, p. 94-102, 2006

MALINA, R. M. Tracking of physical activity and physical fitness across the lifespan. Research Quarterly for Exercise \& Sport, v. 67, p. 48-57, 1996.

MELO JUNIOR, A. S.; RODRIGUES, C. L. P. Avaliação de estresse e dor nos membros superiores em operadores de caixa de supermercado na cidade de João Pessoa: estudo de caso. In: ENCONTRO NACIONAL DE ENGENHARIA DE PRODUÇÃO, 15, 2005, Porto Alegre. Anais... (1 CD-ROM).

OLIVEIRA, J. T. Aspectos comportamentais das síndromes de dor crônica. Arquivos de Neuropsiquiatria, v. 58, n. 2A, p. 360-365, 2000.
PICOLOTO, D.; SILVEIRA, E. Prevalência de sintomas osteomusculares e fatores associados em trabalhadores de uma indústria metalúrgica de Canoas - RS. Ciência \& Saúde Coletiva, v. 13, n. 2, p. 507-516, 2008.

PINHEIRO, F. A.; TRÓCCOLI, B. T.; CARVALHO, C. V. Validação do Questionário Nórdico de Sintomas Osteomusculares como medida de morbidade. Revista de Saúde Pública, v. 36, n. 3, p. 307-12, 2002.

RODACKI, A. L. F. et al. The effect of handling products of different weights on trunk kinematics of supermarket cashiers. International Journal of Industrial Ergonomics, v. 36, p. 129-134, 2006.

SALIM, C. A. Doenças do trabalho: exclusão, segregação e relações de gênero. São Paulo em Perspectiva, v. 17, n. 1, p. 11-24, 2003.

SILVA, F. C. M. Experiência da Dor Crônica: Compreendendo as Repercussões na Participação de Trabalhadores. Belo Horizonte, 2007. 63 p. Dissertação (Mestrado em Ciências da Reabilitação) - Escola de Educação Física, Fisioterapia e Terapia Ocupacional, UFG.

SOUZA, C. C. Ergonomia: análise ergonômica do trabalho dos operadores de caixa de um supermercado. 2007. Monografia (Graduação em Administração), Pontifícia Universidade Católica de Minas Gerais.

SOUZA, G. M.; ALMEIDA, F. S. Queixa de dor músculo-esquelética das atletas de 6 a 20 anos praticantes de ginástica artística feminina. Arquivos Médicos do ABC, v. 31, n. 2, p. 67-72, 2006

TEIXEIRA, C. S. et al. O trabalho de operadores de checkout: dor/desconforto associada às atividades In: CONGRESSO BRASILEIRO DE ERGONOMIA, 15, 2008, Porto Seguro. Anais... (1 CD-ROM).

THOMAS, J. R.; NELSON, J. K. Métodos de pesquisa em atividade física. Porto Alegre: ArtMed, 2002. 419 p.

TRELHA, C. S. et al. Análise de posturas e movimentos de operadores de checkout de supermercado. Fisioterapia em Movimento, v. 20, n. 1, p. 45-52, 2007.

\section{SOBRE OS AUTORES}

\section{Clarissa Stefani Teixeira}

Universidade Federal de Santa Catarina - UFSC, Florianópolis, SC, Brasil

E-mail: clastefani@gmail.com

\section{Maricel Karina López Torres}

Universidade Federal de Santa Catarina - UFSC.

Florianópolis, SC, Brasil

E-mail: celdesigner@gmail.com

\section{Antonio Renato Pereira Moro, Dr.}

Universidade Federal de Santa Catarina - UFSC

Florianópolis, SC, Brasil

E-mail:moro@cds.ufsc.br

\section{Eugenio Andrés Díaz Merino, Dr.}

Universidade Federal de Santa Catarina - UFSC Florianópolis, SC, Brasil

E-mail:merino@deps.ufsc.br 